\title{
Phylogenetic relationships of industrial chicory varieties revealed by RAPDs and AFLPs
}

\author{
G Koch*, C Jung \\ Institut für Pflanzenbau und Pflanzenzüchtung, Christian-Albrechts-Universität zu Kiel, Olshausenstr 40, 24118 Kiel, Germany
}

(Received 12 February 1997; accepted 4 August 1997)

\begin{abstract}
Summary - Seventeen industrial chicory varieties were subjected to molecular marker analysis revealing genetic variation within varieties and genetic relationships between varieties. Banding profiles from 66 RAPD loci (random amplified polymorphic DNA) and 171 AFLP loci (amplified fragment length polymorphism) were produced with total genomic chicory DNA of leaf bulks from four to eight plants per variety. The DICE similarity index was calculated and transformed to genetic distances for construction of phylogenetic trees. We found that there was no clear and strict grouping of the varieties. Genetic distances were nearly the same between all varieties. Marker analysis of individual plants of the variety Fredonia revealed a considerable degree of intravarietal variation typical for open pollinated varieties. The following conclusions were drawn: 1) among the root chicory varieties distant phylogenetic groups do not exist or formerly existing groups were eroded by successive intercrosses; 2 ) potentially existing phylogenetic or heterotic group structures are concealed by the high within population genetic variability; 3 ) the selection/breeding intensities were low during the last decades; and (4) the high degree of genetic variability can be used for selecting superior genotypes from already existing varieties by mass selection.
\end{abstract}

root chicory / Cichorium intybus / phylogeny / molecular markers / RAPDs / AFLPs

Résumé - Relations phylogénétiques entre variétés de chicorée industrielles établies à partir de locus RAPD et AFLP. Dix-sept variétés de chicorée industrielle ont été analysées et les marqueurs moléculaires ont permis de révéler la variabilité génétique intravariétale et les relations génétiques entre ces variétés. Les profils de bandes correspondants à 66 locus RAPD (random amplified polymorphic DNA) et à 171 locus AFLP (amplified fragment length polymorphism) ont été obtenus à partir d'ADN génomique total de mélanges de feuilles de quatre à huit individus par variété. L'indice de similarité DICE a été calculé et transformé en distances génétiques pour construire des arbres phylogénétiques. Aucun regroupement clair et bien individualisé $n$ 'a été observé entre les variétés. Les distances génétiques entre variétés étaient toutes du même ordre de grandeur. L'analyse de plantes individuelles de la variété Fredonia a révélé une importante variabilité intravariétale typique de variétés en fécondation libre. Cette analyse a permis de tirer les conclusions suivantes : i) parmi les variétés de chicorée à racine il n'existe pas de groupes phylogénétiquement distants ou bien les groupes anciennement distants n'existent plus du fait des intercroisements successifs, ii) d'éventuelles structures de groupes phylogénétiques ou hétérotiques sont masquées par la forte variabilité génétique intrapopulation,

Article communicated by Stephen Barnes (Tienen)

* Correspondence and reprints

Tel.: (49) 431880 3215; fax: (49) 431880 2566; e-mail: georgk@ @lantbreeding.uni-kiel.de 
iii) l'intensité de sélection a été faible pendant les dernières décades et iv) le haut niveau de variabilité génétique peut être utilisé pour sélectionner des génotypes supérieurs à partir d'une sélection massale des variétés existantes.

Cichorium intybus / chicorée à racine / phylogénie / marqueurs moléculaires / RAPD / AFLP

\section{INTRODUCTION}

The industrial or root chicory, Cichorium intybus $\mathrm{L}$ var sativum, belongs to the family Asteraceae. Chicory is a biennial crop which is mainly crossfertilised by insects. The primitive form of root chicory is the wild chicory, $C$ intybus $\mathrm{L}$ var intybus. Chicory roots are processed and used as coffee substitute or additive and for inulin production. In addition to industrial chicory, another important chicory, $C$ intybus L var foliosum (witloof, Brussels chicory, French endive, red chicory, Radicchio rosso), is cultivated for its leaves (Mansfeld, 1986)

Inulin, a $\beta-(2,1)$-linked fructan, is the major reserve carbohydrate in many Asteraceae, eg, chicory, Jerusalem artichoke, dahlia. Improved techniques in cultivation of chicory roots and new food and non-food applications for chicory inulin (Fuchs, 1987, 1993; Soja, 1992) have increased the production of root chicory. In field experiments, yield of dried root mass ranged from 10.6 to $16.5 \mathrm{t} \mathrm{ha}^{-1}$ and inulin yields from 8.0 to $12.6 \mathrm{t} \mathrm{ha}^{-1}$ (Frese, 1993; Meijer et al, 1993). High genetic variances for yield and inulin content between varieties were reported (Coppens D'Eeckenbrugge et al, 1989; Dutilleul et al, 1990; van Herck et al, 1992; Steinmayr, Sarea, Austria, pers comm) suggesting that the yield potential can still be increased by breeding (Frese et al, 1991).

Breeding is complicated by the strict outcrossing nature of this species, its biennial character, the total or partial self-incompatibility and the lack of a reliable cms-system (Eenink, 1981; Rambaud et al, 1993). Recently a genetically modified hybrid variety of Radicchio rosso was brought into the market using the seedlink ${ }^{\mathrm{TM}}$ technology for inducing male sterility. This technique may also have some impact on root chicory breeding in the future. Since morphological markers are not available for this species molecular markers can be employed for i) assessing the genetic variability within and between breeding lines or populations; ii) identifying heterotic groups for hybrid breeding; and iii) verifying the hybrid nature of seeds from controlled crosses. To date, few reports have been given on marker analyses. Restriction analysis of mtDNA revealed only minor differences between species of the genus Cichorium (Vermeulen et al, 1994). The variability between varieties of chicory using isozyme markers was found to be low (Baes and Van Cutsem, 1993a, b). With RAPD analysis of a sample of seven witloof inbred lines and an $F_{1}$ hybrid clear differences between the inbred lines were found (Bellamy et al, 1995, 1996). However, overall genetic variability was low, indicating a narrow genetic basis in the witloof breeding lines. Recently, progress in establishing a linkage map with AFLP markers has been presented by DeSimone et al (1996) encompassing 364 markers, which assembled to a framework map covering $1060 \mathrm{cM}$. Until now, the genetic variability and relationships between and within root chicory varieties are unknown.

The objective of this work was to assess the genetic distances between 17 root chicory varieties with the help of RAPD and AFLP markers. Another scope of this study was to compare the results obtained from those different marker systems with respect to reliability and applicability for chicory breeding. PCR (polymerase chain reaction)-based markers were chosen for the phylogenetic analysis, because of their broad applicability, a high potential for screening of large populations and independence from phenotype.

\section{MATERIALS AND METHODS}

\section{Germplasm and DNA isolation}

The chicory varieties were chosen according to their economic importance. They were supplemented with some older varieties, landraces and three individual plants from the variety Fredonia not used for the variety sample (table I). Seeds were kindly supplied by L Frese, FAL (Genbank), Braunschweig. Plants were grown in the greenhouse until eight leaves were fully expanded. From each variety young leaves from four to eight plants were harvested in equal amounts, pooled, freeze-dried and crushed in a swing mill. DNA extraction was performed according to Saghai-Maroof et al (1984). All marker reactions were performed with these leaf-bulked DNAs. 
RAPDs

PCR was performed with $30 \mathrm{ng}$ of DNA per reaction according to the protocol of Operon Technologies Inc, USA (cf Williams et al, 1990). PCR products were separated on $2 \%$ agarose gels, stained with ethidium bromide and scored for absence/presence of the bands on a UV transilluminator. The Operon primers A8, A9, A10, A11, A13, AH5, AH6, AH8 and AH9 were employed.

PCR reactions were performed in a $25 \mu \mathrm{L}$ reaction volume with $10 \mathrm{mM}$ TRIS pH 9.0, $50 \mathrm{mM} \mathrm{KCl,} 2 \mathrm{mM}$ $\mathrm{MgCl}_{2}, 0.1 \mathrm{mM}$ dNTPs, 7.5 pmol RAPD-Primer (Operon), 0.5 U Taq DNA polymerase (Pharmacia, Sweden) in a Perkin-Elmer (USA) T480 thermocycler. Cycle reaction started with an initial denaturation of 3 min at $94{ }^{\circ} \mathrm{C}$, followed by 45 cycles with: $1 \mathrm{~min}$ at $94{ }^{\circ} \mathrm{C}, 1 \mathrm{~min}$ at $36^{\circ} \mathrm{C}, 2 \mathrm{~min}$ at $72^{\circ} \mathrm{C}$ and a final extension for $10 \mathrm{~min}$ at $72^{\circ} \mathrm{C}$.

\section{AFLPs}

AFLPs were generated as described by Vos et al (1995). Here, $100 \mathrm{ng}$ of genomic DNA was double digested with $E c o$ RI and $M s e I$ and ligated to $E c o$ RI and $M$ seI-adapters. Preamplifications were performed with $\mathrm{P}+1$ EcoRI- and MseI-primers. P+3 EcoRI-primers were end-labelled with $\left[\gamma-{ }^{33} \mathrm{P}\right] \mathrm{ATP}(2000 \mathrm{Ci} / \mathrm{mmol})$. Amplifications of specific primer combinations were performed with the end-labelled $\mathrm{P}+3$ EcoRI-primer and a non-labelled P+3 Msel-primer. All PCRs were performed with a Perkin Elmer PE9600 thermocycler. PCR products were mixed with an equal volume of formamide dye (98\% formamide, $10 \mathrm{mM}$ EDTA, $0.025 \%$ $(\mathrm{w} / \mathrm{v})$ bromo phenol blue, $0.025 \%(\mathrm{w} / \mathrm{v})$ xylene cyanol) and denatured for $3 \mathrm{~min}$ at $90^{\circ} \mathrm{C}$. Three microlitres of each sample were separated for $100 \mathrm{~min}$ at constant $60 \mathrm{~W}$ on standard sequencing gels. Gels were dried after electrophoresis and exposed for 3-6 days on $\beta$ max Hyperfilm (Amersham, UK). The primer sequences are given below:

\author{
EcoRI-adapter: \\ 5'-CTCGTAGACTGCGTACC -3' \\ 3'-CTGACGCATGGTTAA-5' \\ EcoRI-primer+1 (preamplification): \\ 5'-GACTGCGTACCAATTC A-3' \\ EcoRI-primer+3 (amplification): \\ EcoRI+3:5' -GACTGCGTACCAATTC ANN-3'
}

\author{
MseI-adapter: \\ 5'-GACGATGAGTCCTGAG -3' \\ 3'-TACTCAGGACTCAT-5'
}

MseI-primer+1 (preamplification):

5'-GATGAGTCCTGAGTAA C-3'

MseI-primer+3 (amplification):

Mse I+3:5'-GATGAGTCCTGAGTAA CNN-3'

Table I. Root chicory varieties in a phylogenetic analysis with RAPD and AFLP markers.

\begin{tabular}{lcc}
\hline Variety & Year of registration & Breeder, country of origin \\
\hline Landraces or old varieties & & CSSR \\
Slezka & unknown & CSSR \\
Spicak & unknown & Royal Sluis \\
Luxor & unknown & Royal Sluis \\
Wixor & unknown & Wagner \\
Magdeburger Spitzkopf & unknown & \\
& & RvP \\
Registered varieties, no longer in use or no longer publically available & Desprez \\
Novipa & 1956 & Desprez \\
Fruitosa & 1984 & Desprez \\
Pevele & 1984 & \\
Lys & unknown & \\
Varieties presently used for root chicory cultivation & & DvLaue; RvP \\
Dageraad & 1981 & SES; Bataille-Alphonse \\
Tilda & 1984 & Desprez \\
Cassel & 1986 & SES; Selbat \\
Candi & 1986 & Desprez \\
Orchies & 1987 & SES; Bataille-Alphonse \\
Hicor & 1988 & SES; Selbat \\
Inula & 1988 & Sarea \\
Fredonia & unknown &
\end{tabular}

aEEC Common Catalogue (17th edition). 
AFLP banding patterns of the following seven primer combinations were performed: $E c o \mathrm{RI}+\mathrm{ACA} / M s e \mathrm{I}+\mathrm{CTT}, \quad E c o \mathrm{RI}+\mathrm{ACT} / M s e \mathrm{I}+\mathrm{CAT}$, $E c o \mathrm{RI}+\mathrm{AGC} / M s e \mathrm{I}+\mathrm{CGT}, \quad E c o \mathrm{RI}+\mathrm{AGC} / M s e \mathrm{I}+\mathrm{CTA}$, $E c o \mathrm{RI}+\mathrm{AGC} / M s e \mathrm{I}+\mathrm{CTG}, E c o \mathrm{RI}+\mathrm{ACC} / M s e \mathrm{I}+\mathrm{CAA}$, EcoRI+ACC/MseI+CAC

\section{Calculation of similarities using binary scores for band absence/presence}

The RAPD and AFLP patterns were scored for absence/presence of the bands in each sample. Due to the pooling of several individuals in each sample, band intensities varied among samples. RAPD bands were scored ignoring band intensities and AFLP bands were scored only for bands with similar band intensities among samples. Only clearly reproducible bands were scored. Bands that were visible in all samples (monomorphic loci) were omitted in the 0/1-matrix produced for calculation of the DICE similarity, $S_{i j}$, with NTSYS-PC Vers 1.80 (Exeter Software, New York: Rohlf, 1993)

$$
S_{i j}=\frac{2 n_{i j}}{n_{i}+n_{j}}
$$

where $n_{i j}$ is the number of common bands, $n_{i}$ is the number of bands in variety $i$, and $n_{j}$ is the number of bands in variety $j$.

DICE similarities were transformed into distances by applying the transformation of Nei and $\mathrm{Li}$ (1979)

$$
D_{i j}=1-S_{i j}
$$

The normalized Mantel statistic $Z$, implemented in NTSYS-PC Vers 1.80 (Exeter Software, New York: Rohlf, 1993) was applied to test the association between the similarity matrix based on RAPDs and the similarity matrix based on AFLPs.

\section{Construction of phylogenetic trees}

Phylogenetic relationships between varieties were calculated using the Fitch-Margoliash algorithm of the FITCH module from PHYLIP Vers 3.5c (Felsenstein $1989,1993)$ run on a SUN UltraSparc under Solaris. Input order of the populations was randomised (Jumble option) and the global rearrangement of each possible subtree during construction of the tree (Global option) was allowed. Tree construction was repeated 100 times $(J=100)$ with randomised input order and the unrooted tree with the smallest 'percent standard deviation' (Fitch-Margoliash criterion; Weir, 1996) of all runs drawn (branch lengths allowed).

We generally use the term 'phylogenetic relationships' instead of the more accurate term 'phenetic relationships' (Sneath and Sokal, 1973). The classification and grouping of the objects under study is based on their overall similarity and does not reflect evolutionary pathways. These relationships are best represented as phenograms (Weir, 1996).

\section{Calculation of gene diversity (PIC)}

The relative information content of different markers can be compared by calculating a measure of variation, the gene diversity, also known as the polymorphic information content (PIC). This measure is originally calculated from allele frequencies of codominant genes (Weir, 1996). The adaptation to dominant markers violates some assumptions of the sampling properties of gene diversity, but may be used as a rough estimate for comparisons between different markers of the same marker class. The gene diversity is calculated as follows

$$
D_{l}=1-\sum_{l t} \mathrm{p}_{l t}^{2}
$$

(Weir, 1996)

where $p_{l u}$ is the frequency of the $u$ th allele at the $l$ th locus.

At each locus two alleles are assumed: the band and a null allele. Gene diversity, $D_{l}$, is averaged over all loci to compare PIC of RAPDs and AFLPs and designated as PIC. Using dominant markers the estimated PIC has an unknown bias because heterozygous and homozygous individuals cannot be differentiated. The dominant band allele masks the invisible null allele in the case of heterozygous individuals. Consequently, the null allele frequencies are underestimated. Because both marker types, RAPDs and AFLPs, are inherited dominantly and only clearly visible bands were scored the violation of the underlying sampling properties are of minor consequences and tolerable for a simple comparison.

\section{RESULTS}

\section{RAPD analysis}

PCR with 12 RAPD Operon primers was performed without prior selection for the most informative primers. Altogether, 72 band positions were scrored, of which 66 bands were produced from polymorphic loci and six bands from monomorphic loci. The number of bands per primer ranged between one (OP-AH8) and 17 (OP-A8). One primer (OP-A8) gave rise to a complex banding pattern (fig 1). All accessions could be differentiated with this primer owing to individual fingerprinting patterns.

DICE similarities calculated on RAPDs ranged between 0.34 and 0.91 with an average of 0.64 and a standard deviation of 0.11 (table II). Phylogenetic relationships of entries were repre- 
sented in an unrooted tree (fig 2A). Clustering of landraces and varieties based on genetic distances resulted in no distinctive clusters. Distances between internal nodes were several magnitudes smaller than distances between the tips within branches. A possible association of the tree topology with agronomic traits of varieties/landraces is given in table III. The average similarity between the modern varieties of groups IV and $\mathrm{V}$ was slightly higher $(0.78)$ compared to the average similarity between all pairs of varieties (0.64).

A high degree of RAPD polymorphisms was obvious among individual plants of the variety Fredonia (cf fig 1). DICE similarities between the variety sample and the three individual plant samples ranged from 0.70 to 0.85 indicating that Fredonia is a highly heterogeneous variety. However, all individuals clustered in one group together with the variety. The average similarity among the Fredonia sample and the three individual plants of Fredonia was 0.77 . This is nearly the same similarity as the average similarity between all modern varieties used in this study.

\section{AFLP analysis}

AFLP profiles were produced from seven primer combinations without prior selection for the most informative primer pairs. Altogether, 373 AFLP

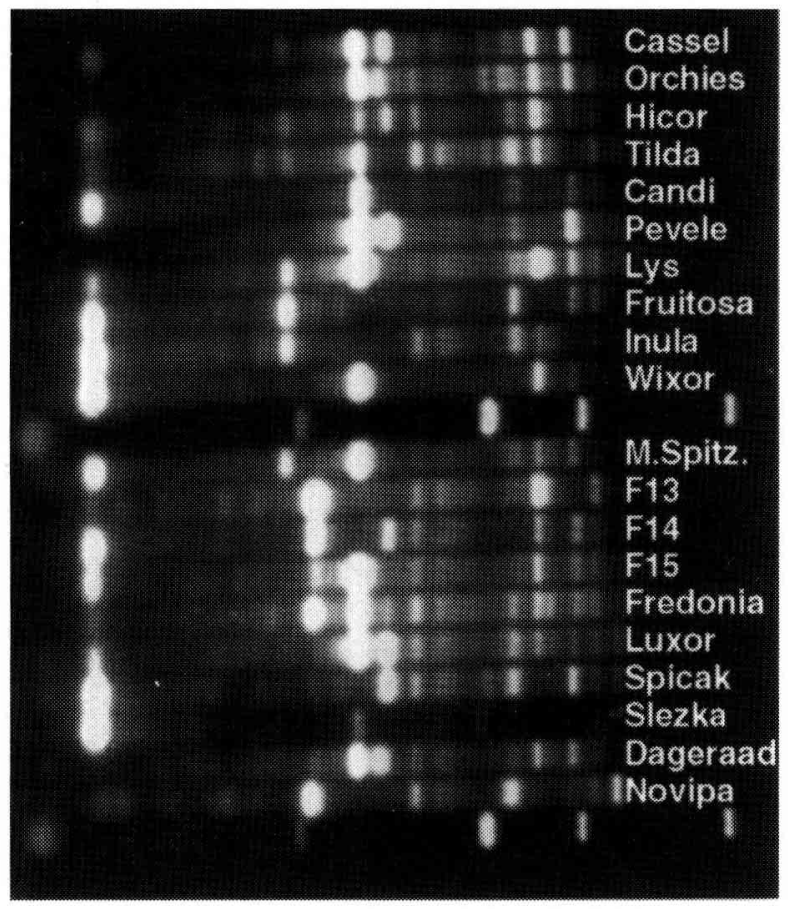

Fig 1. RAPDs of 17 chicory varietics and three individual plants of the variety Fredonia (F13, F14, F15) using Operon primer A8. band positions were scored, of which 202 loci were monomorphic and 171 AFLP loci were polymorphic. An AFLP fingerprint profile is shown in figure 3. Each primer pair produced a complex banding pattern with enough polymorphisms for differentiating all varieties and landraces.

DICE similarities ranged from 0.44 to 0.83 with an average of 0.66 and a standard deviation of 0.09 (table II). No clear clustering into distinctive groups was visible (fig 2B), with the exception of Fredonia and its three individuals, which clustered in a well-separated group. Average similarity of the variety sample of Fredonia and the separately analysed individuals was 0.68 , which was only slightly higher than the average similarity over all entries.

A higher similarity among the modern varieties was obvious, which is comparable to the RAPD analysis. The average similarity based on AFLPS between the modern varieties of cluster IV and $\mathrm{V}$ (cf table III) is 0.76 with a range from 0.71 to 0.80 (table II). However, these entries are not clustered in one or two separate groups.

\section{Comparison between RAPD and AFLP marker analysis}

Band frequencies of RAPDs and AFLPs ranged between 0.05 and 0.95 with an average of 0.43 and 0.54 , respectively. The PIC was nearly identical between RAPDs (0.33) and AFLPs (0.34) with identical ranges between 0.1 and 0.5 , indicating that the information value between RAPDs and AFLPs is comparable. Also the average DICE similarities of the RAPDs and AFLPs did not differ significantly with 0.64 and 0.66 , respectively.

The correlation of RAPD versus AFLP similarities is shown in figure 4 . The pattern of the similarity pairs is characterised by the lack of extremes and centered around the average similarity means. The similarities and matrices calculated from RAPD and AFLP markers were not correlated $(r=0.18$; Mantel test $P=0.185)$.

\section{DISCUSSION}

This study had as objective to assess the genetic relationships between industrial root chicory varieties and landraces using RAPD and AFLP markers. The overall impression from both markerbased phylograms is the high heterogeneity and low group structure of the varieties and landraces 
A

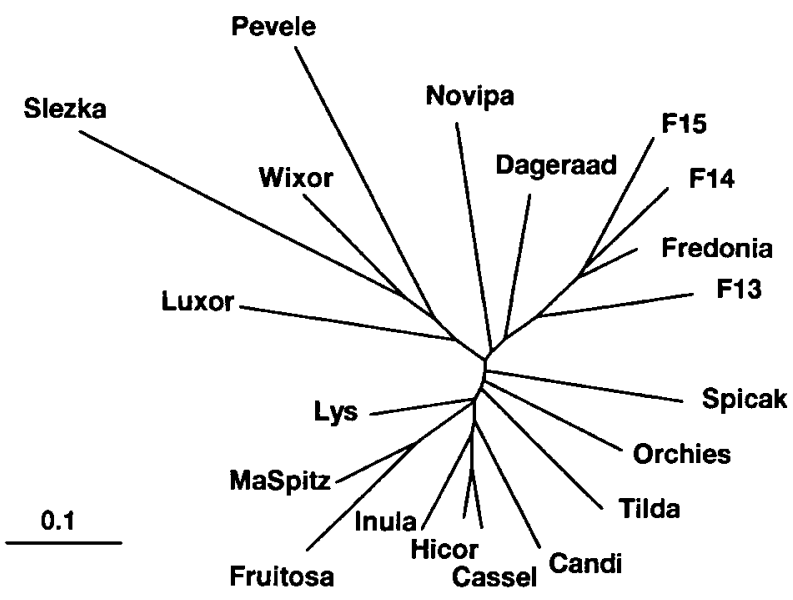

B

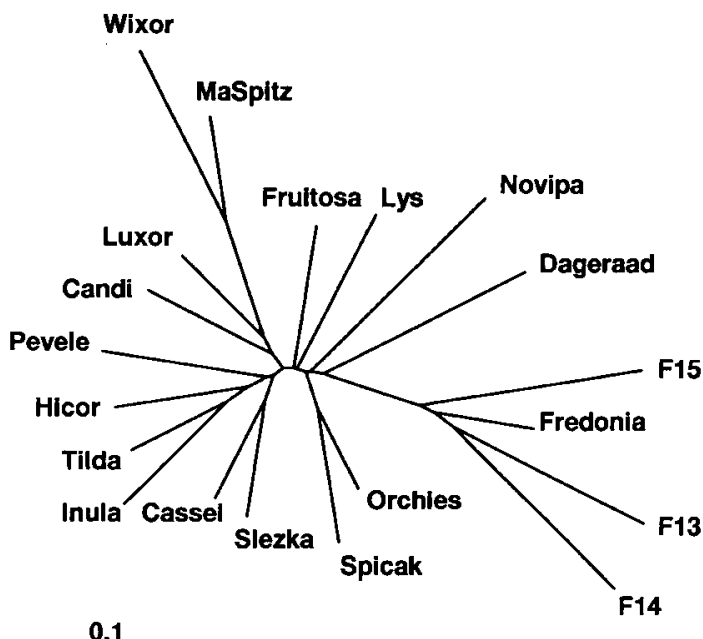

Fig 2. The phylogenetic tree representing relationships among 17 chicory varieties and three individual plants of the variety Fredonia (F13, F14, F15) calculated from genetic distances (1-DICE) of 66 RAPDs (A) and 171 AFLPs (B).

investigated. This is indicated by the low average genetic similarity between samples and the small distances between the internal nodes. In the case of the AFLP-based phylogram a star-like topology is obtained (fig 2B) reflecting that no convergent breeding occurred. Bellamy et al (1996) analysed inbred lines and backcross populations of witloof chicory and found a low level of genetic variability. In the extremes, they found two pairs of lines that revealed polymorphisms only with seven and eight RAPD primers out of 100 primers tested. They assumed a narrow genetic base for witloof owing to convergent breeding and use of the same parental genotypes. In contrast, our results demonstrate that a high degree of genetic diversity is present within and between root chicory varieties. The absence of convergent and also divergent breeding effects may indicate a low breeding intensity during the last decades, which has not resulted in a reduction of the genetic base through the use of common ancestors and inbreeding thus promising a high breeding potential. Evidence for the high breeding potential of root chicory was given by Frese et al (1991), who showed significant variation between polycross families. Total sugar yield was in 12 out of 72 polycross families increased by 15 to $24 \%$.

Here, we have used the novel AFLP marker technique in combination with the established RAPD technique. The advantage of AFLPs over RAPDs lies in a higher number of polymorphic markers that can be produced with similar efforts and with a higher reproducibility. First results using AFLPs to estimate the relationships between varieties showed that relationships based on AFLP marker data are well suited to predict phylogenies from known pedigrees (Hayes et al, 1996; Peerbolte and Peleman, 1996; Walton et al, 1996) and phylogenies deduced from AFLP and RAPD marker data revealed comparable results (Lu et al, 1996; Sharma et al, 1996). Also, RAPDs are widely used as genetic markers for phylogenetic analysis (dos Santos et al, 1994; Morell et al, 1995).

Chicory is an outbreeder and most root chicory varieties are population varieties. We considered the putative heterogeneous variety structure in the sampling strategy. The pooling of four to eight individuals in each sample increased the chance of sampling the predominant alleles. It prevented us from attributing rare alleles as variety-specific alleles and reduced sampling bias. Otherwise differences in the band intensities complicated the band scoring, especially for the RAPD bands. Up to ten individuals per sample can be pooled without loss of singular RAPD alleles (Michelmore et al, 1991). However, this leads to more or less faint bands, which are not quantitatively exploitable. Due to the large number of polymorphic AFLP loci, bands with similar intensities could be chosen for the scoring of the AFLP profile. To evade these methodological problems allele frequencies should be estimated within each population. This could be carried out by individual marker analyses 


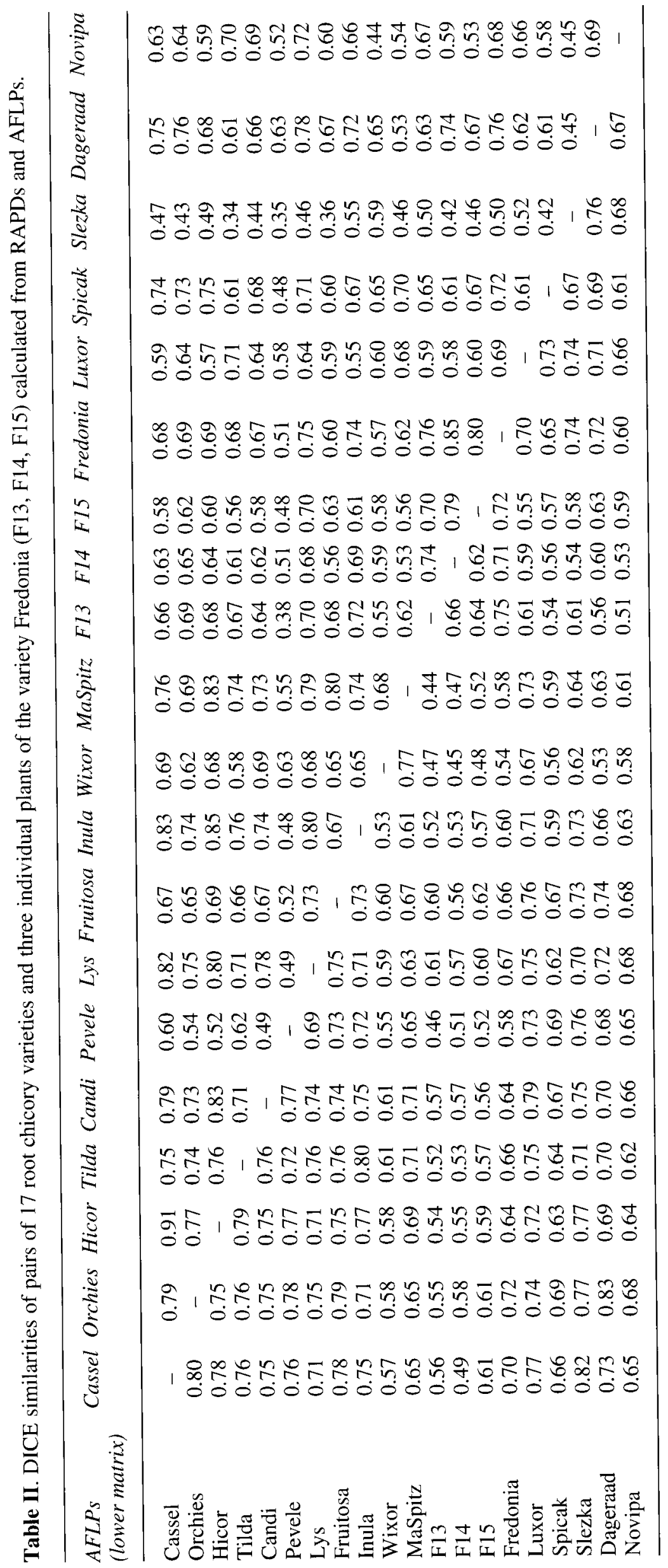




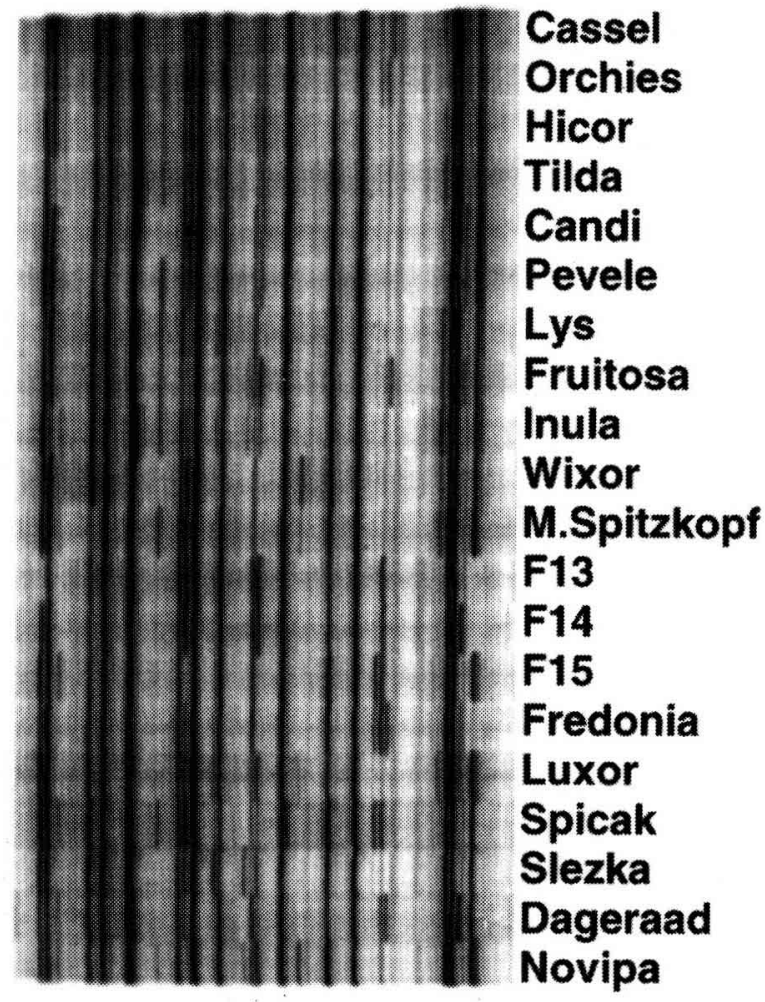

Fig 3. AFLP banding pattern produced with the primer combination $E c o \mathrm{RI}+\mathrm{ACT} / M$ se I+CAT of 17 chicory varieties and three individual plants of variety Fredonia (F13, F14, F15).

of a larger number of individuals per variety or by a pooled sampling strategy with a reliable quantitative band scoring. For the latter approach no method is available yet and the analysis of a large number of individuals is expensive and laborious. Another approach is to analyse multiple small pools of individuals per population and to construct phylogenies mainly based on populationspecific alleles (cf Smouse et al, 1982).

The comparison of phylograms deduced from RAPD and AFLP markers of the investigated root chicories is complicated by the unknown pedigree of the varieties and the high diversity found with both marker systems. Conformity in tree topologies were only found for the Fredonia branch (group I). Clustering based on RAPDs was slightly more pronounced. However, entries from the same clusters showed only a slightly higher similarity than entries of different clusters. We therefore assume that a strict phylogenetic clustering does not exist and that differences between the true genetic distances of the varieties are small.

We have not included an outgroup taxa. The inclusion of one or more outgroups are recommended in cladistic analysis as a means of testing the assumption of monophyly. It provides additional information for the interpretation of the ingroup heterogeneity and it would allow the tree to be rooted. However, using the FitchMargoliash algorithm long distances in the tree will tend to compound errors. Long distances in the trees were found both with RAPD and AFLP data. The inclusion of an outgroup taxon, eg, Spinacia oleracera L, would probably further attribute errors to the tree topology. Otherwise varieties and landraces can be considered with high certainly as a monophyly and the tree topologies presented for both marker systems are obviously heterogeneous. Another argument against the inclusion of an outgroup is the hemi-locus specificity of the PCR markers applied. In a phylogenetic study with Beta vulgaris $\mathrm{L}$ and several wild beet accessions we observed completely different AFLP profiles between these Beta species (data unpublished). Large differences in the DNA profiles may indicate a violation of the assumption that amplified DNA fragments of the same length are derived from the same locus. For the given reasons no outgroup taxon was included.

Considering this low degree of phylogenetic differentiation obtained with both marker systems and the unknown relationships between the varieties, differences between clustering based on

Table III. Grouping of chicory varieties based on genetic distances calculated from RAPDs and agronomic traits.

\begin{tabular}{lcc}
\hline Group & \multicolumn{1}{c}{ Varieties } & Description $^{\mathrm{a}}$ \\
\hline $\begin{array}{l}\text { Fredonia group } \\
\text { Old varieties }\end{array}$ & Fredonia, Novipa, Dageraad, Spicak & Varieties with a high dry matter content \\
Old varieties & Wixor, Pevele, Slezka, Luxor & Varieties useful as genetic resources \\
Modern varieties & Lys, Fruitosa, Magdeburger Spitzkopf & Varieties useful as genetic resources \\
Modern varieties & Hicor, Cassel, Inula & $\begin{array}{c}\text { Varieties with high yield potential; } \\
\text { dry matter content lower than in Fredonia } \\
\text { Varieties with high yield potential; }\end{array}$ \\
& Tilda, Orchies, Candi & dry matter content lower than in Fredonia
\end{tabular}

aPersonal communication from the chicory breeders and results from field trials (Coppens d'Eeckenbrugge et al, 1989; Dutilleul et al, 1990; van Herck et al, 1992). 


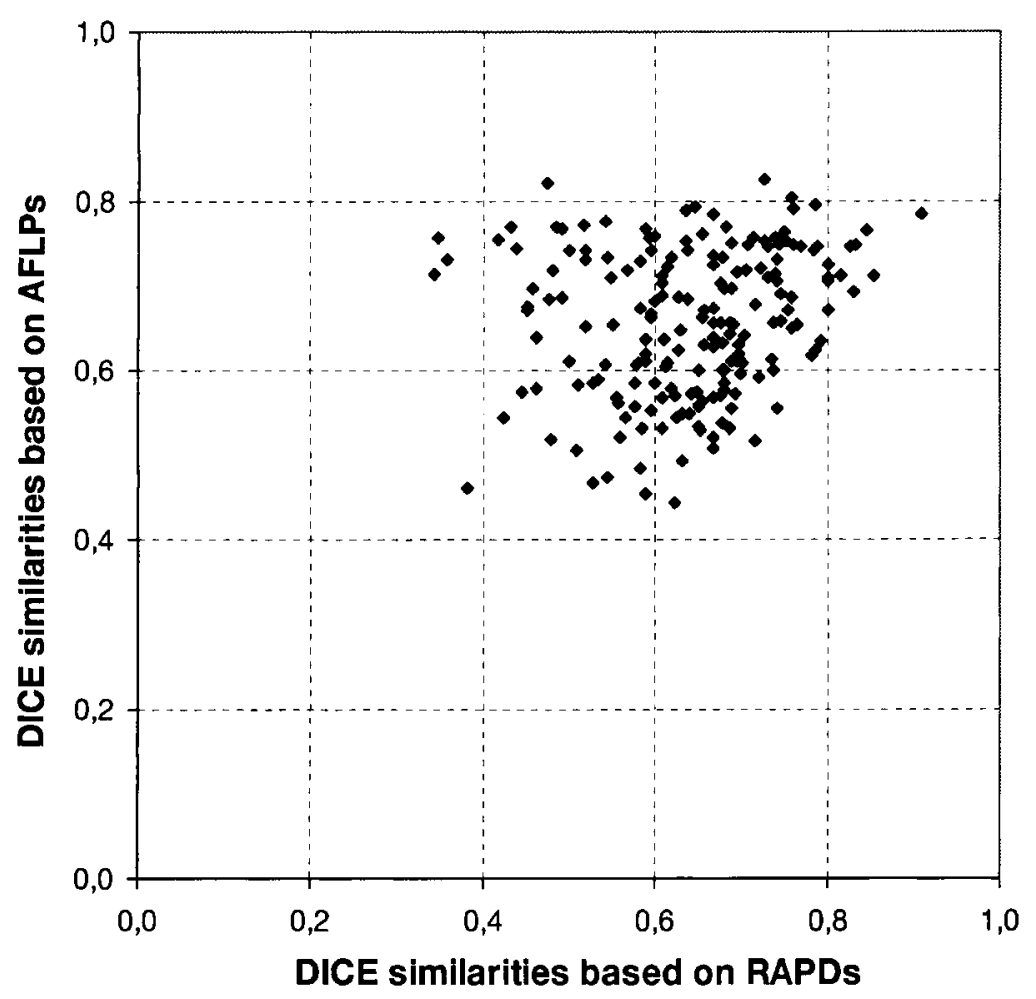

Fig 4. Correlation of DICE similarities based on RAPDs and AFLPs of 17 chicory varieties and three individual plants of the variety Fredonia (F13, F14, F15). The matrix correlation is: $r=0.18$ and the onetail propability (matrices not correlated) is: $P=0.185$.
RAPDs and AFLPs do not reflect true differences. They may be due to sampling errors or bias caused by the dominant inheritance of both markers. These error terms always contribute to the total variance in phylogenetic marker analysis. Concerning our comparison between RAPD and AFLP phylogenies from root chicory varieties, the unknown variance from these error terms may be larger than the genetic variance, which explains the observed uncorrelated similarities and random differences in the tree topologies.

As a consequence of the unknown chromosomal position of the markers multiple sampling of the same chromosomal region may occur resulting in a biased estimate of genetic distances. Comparative mapping with AFLP and RFLP markers in sugar beets (Schondelmaier et al, 1996) and other species (cf Kesseli et al, 1994) demonstrated that markers are generally not randomly distributed around linkage groups. These results also show that PCR markers do not contribute more to the clustering of loci than RFLPs. To avoid the unequal distribution of marker loci employed in phylogenetic analysis, previously mapped markers are used.

From the data presented here, the following conclusions can be drawn: i) selection/breeding intensities were low during the last decades; ii) distant phylogenetic groups do not exist or formerly existing groups were eroded by successive intercrosses and use of these genetic resources in practical breeding; iii) the potentially existing phylogenetic or heterotic group structures are hidden by a high within population variability offering the possibility for mass selection from already existing varieties to breed superior root chicory.

Acknowledgements: We thank M Bruisch for her skilful technical assistance and HP Piepho for helpful comments on the manuscript.

\section{REFERENCES}

Baes P, Van Cutsem P (1993a) Electrophoretic analysis of eleven isozyme systems and their possible use as biochemical markers in breeding of chicory (Cichorium intybus L). Plant Breeding 110, 16-23

Baes PG, Van Cutsem PJ (1993b) Isozyme polymorphism in three gene pools of cultivated chicory (Cichorium intybus L). Euphytica 71, 143-150

Bellamy A, Mathieu C, Vedel F, Bannerot H (1995) Cytoplasmic DNAs and nuclear rDNA restriction fragment length polymorphisms in commercial witloof chicories. Theor Appl Genet 91, 505-509

Bellamy A, Vedel F, Bannerot H (1996) Varietal identification in Cichorium intybus $\mathrm{L}$ and determination of genetic purity of $\mathrm{F}_{1}$ hybrid seed samples, based on RAPD markers. Plant Breeding 115, 128-132

Coppens d'Eeckenbrugge G, van Herck J-C, Dutilleul $\mathrm{P}$ (1989) A study of fructose yield components in chicory. Plant Breeding 102, 296-301 
DeSimone M, Marocco A, Lucchin M, Parrini P, Morgante M (1996) A saturated linkage map of chicory (Cichorium intybus) using a pseudo-testcross and AFLP, SAMPL and RAPD markers. Plant Genome IV, San Diego, Poster 259

Dos Santos JB, Nienhuis J, Skroch P, Tivang J, Slocum MK (1994) Comparison of RAPD and RFLP genetic markers in determining genetic similarity among Brassica oleracea L genotypes. Theor Appl Genet 87, 909-915

Dutilleul P, van Herck J-C, Coppens d'Eeckenbrugge G (1990) Analyse multivariée des paramètres liés au rendement en inuline et à la pureté de la chicorée industrielle (Cichorium intybus L). Rev Agric (Bruss) 43, 539-547

Eenink AH (1981) Compatibility and incompatibility in witloof chicory (Cichorium intybus L). 2. The incompatibility system. Euphytica $30,77-85$

Felsenstein J (1989) PHYLIP - phylogeny inference package (Version 3.2). Cladistics 5, 164-166

Felsenstein J (1993) PHYLIP (phylogeny inference package) version $3.5 \mathrm{c}$. Distributed by the author. Department of Genetics, University of Washington, Seattle

Frese L (1993) Production and utilization of inulin. Part I. Cultivation and breeding of fructan-producing crops. In: Science and Technology of Fructans (Suzuki M, Chatterton NJ, eds), CRC Press, Boca Raton, 303-317

Frese L, Dambroth M, Bramm A (1991) Breeding potential of root chicory (Cichorium intybus $\mathrm{L}$ var sativum). Plant Breeding 106, 107-113

Fuchs A (1987) Potentials for non-food utilization of fructose and inulin. Starch 39, 335-343

Fuchs A (1993) Production and utilization of inulin. Part II. Utilization of inulin. In: Science and Technology of Fructans (Suzuki M, Chatterton NJ, eds), CRC Press, Boca Raton, 319-352

Hayes PM, Chen F, Kuiper M, Zabeau M, Kleinhofs A, Saghai-Maroof M, Hoffman D (1996) Application of AFLP markers to map construction and diversity analysis in barley. Plant Genome IV, San Diego, Poster 136

Kesseli RV, Paran I, Michelmore RW (1994) Analysis of a detailed genetic linkage map of Lactuca sativa (lettuce) constructed from RFLP and RAPD markers. Genetics 136, 1435-1446

Lu J, Knox MR, Ambrose MJ, Brown JKM, Ellis THN (1996) Comparative analysis of genetic diversity in pea assessed by RFLP- and PCR-based methods. Theor Appl Genet 93, 1103-1111

Mansfeld R (1986) Verzeichnis landwirtschaftlicher und gärtnerischer Kulturpflanzen. AkademieVerlag, Berlin, edition 3, 1324-1326

Morell MK, Peakall R, Appels R, Preston LR, Lloyd HL (1995) DNA profiling techniques for plant variety identification. Aust J Exp Agric 35, 807-819
Meijer WJM, Mathijssen EWJM, Borm GEL (1993) Crop characteristics and inulin production of Jerusalem artichoke and chicory. In: Inulin and Inulin-containing Crops (Fuchs A, ed), Elsevier, Amsterdam, 29-38

Michelmore RW, Paran I, Kesseli RV (1991) Identification of markers linked to disease-resistance genes by bulked segregant analysis: A rapid method to detect markers in specific genomic regions by using segreagating populations. Proc Natl Acad Sci USA 88, 9828-9832

Nei M, Li W (1979) Mathematical model for studying genetic variation in terms of restriction endonucleases. Proc Natl Acad Sci USA 76, 5256-5273

Peerbolte R, Peleman J (1996) AFLP (TM) fingerprinting technology to estimate genetic distances in sunflower. Plant Genome IV, San Diego, Poster 323

Rambaud C, Dubois, J, Vasseur J (1993) Male-sterile chicory cybrids obtained by intergeneric protoplast fusion. Theor Appl Genet 87, 347-352

Rohlf FJ (1993) NTSYS-pc Version 1.80. Numerical Taxonomy and Multivariate Analysis System. Exeter Software, New York

Saghai-Maroof MA, Soliman KM, Jorgensen RA, Allard RW (1984) Ribosomal DNA spacer-length polymorphisms in barley: mendelian inheritance, chromosomal location and population dynamics. Proc Natl Acad Sci USA 81, 8014-8018

Schondelmaier J, Steinrücken G, Jung C (1996) Integration of AFLP markers into a linkage map of sugar beet. Plant Breeding 1 15, 231-237

Sharma SK, Knox MR, Ellis THN (1996) AFLP analysis of the diversity and phylogeny of Lens and its comparision with RAPD analysis. Theor Appl Genet $93,751-758$

Smouse PE, Spielman RS, Park MH (1982) Multiplelocus allocation of individuals to groups as a function of the genetic variation within and differences among human populations. The American Naturalist $119,445-463$

Soja G (1992) Fruktanforschung in Österreich, Deutschland und den Niederlanden. OEFZS-Bericht 4621, Forschungszentrum Seibersdorf, Austria

Sneath PHA, Sokal RR (1973) Numerical Taxonomy. Freeman, San Francisco, CA

Van Herck J-C, Coppens d'Eeckenbrugge G, Dutilleul P (1992) Évolution des composantes du rendement en fructose de la racine de chicorée industrielle (Cichorium intybus $\mathrm{L}$ ) au cours de la campagne de récolte. Rev Agric (Bruss) 45, 7-18

Vermeulen A, Desprez B, Lancelin D, Bannerot H (1994) Relationships among Cichorium species and related genera as determined by analysis of mitochondrial RFLPs. Theor Appl Genet 88, 159-166

Vos P, Hogers R, Bleeker M, Reijans M, van de Lee T, Hornes M, Frijters A, Pot J, Peleman J, Kuiper M, Zabeau M (1995) AFLP: a new technique for DNA fingerprinting. Nucleic Acids Res 23, 4407-4414 
Walton M, Wright S, Hookstra G (1996) A comparison of genetic similarity estimates among 16 maize inbred lines based upon RFLP and AFLP data. Report available at Linkage Genetics, 2411 South 1070 West Suite B, Salt Lake City, UT 84119, USA

Weir BS (1996) Genetic Data Analysis II. Sinauer, Sunderland, MA
Williams JGK, Kubelik AR, Livak KJ, Rafalski JA, Tingey SV (1990) DNA polymorphisms amplified by arbitrary primers are useful as genetic markers. Nucleic Acids Res 18, 6531-6535 